\title{
ANALISIS KENAIKAN PANGKAT DAN JABATAN DOSEN POLITEKNIK KESEHATAN
}

\author{
Ni Nyoman Kasihani \\ Jurusan Keperawatan Gigi Poltekkes Kemenkes Jakarta I
}

\begin{abstract}
Lecturer is one of the most important components in the organization of higher education. Promotion and position is a trust and appreciation given to the lecturer for the achievements that have been achieved. Obtain information of factors related to promotion and position of lecturer at Health Polytechnic of Ministry of Health. Cross Sectional method research in June-October 2017. Data collected using Likert Scale Questionnaire. The research was conducted on permanent lecturer of Health Polytechnic of Kemenkes Jakarta I who has functional position of 60 people. Sample amounted to 47 people (response rate $78.33 \%$ ). Data were processed and analyzed univariate, bivariate and multivariate. Lecturers characteristic variable has no significant correlation with promotion and position of lecturer with $\mathrm{p}$ value $>0,05$. Components of PAK that have significant relationship with promotion and lecturers position are education and teaching variables with $\mathrm{p}$ value 0,024 and value of OR 19,808 and research variable with $\mathrm{p}$ value 0,007 value OR 40,798. The variable of community service and supporting activities is not significant with $p$ value $>0,05$. PAK management system has a significant with $\mathrm{p}$ value 0,004 value OR 19,918 . Significant variable on promotion and position of lecturers is education and teaching, research and management system of PAK. The variable that has the greatest relationship with promotion and position of lecturer is research. An intensive training for lecturers is required for the publication of scientific papers in national and international journals and to reward lecturers who publish scientific works to improve motivation to work.
\end{abstract}

Keywords: Lecturer, promotion, position

\section{PENDAHULUAN}

Dosen sebagai salah satu komponen penting dalam pendidikan tinggi dan mempunyai peran yang sangat signifikan bagi perguruan tinggi dalam menjalankan fungsinya. Dosen adalah jabatan fungsional yang harus mengumpulkan angka kredit untuk kenaikan pangkat dan jabatannya dan dapat naik pangkat paling cepat 2 tahun apabila telah memenuhi syarat angka kredit yang dipersyaratkan.

Kenaikan pangkat dosen Poltekkes Kemenkes Jakarta I berdasarkan data bulan April 2017 terdapat 36,6 \% dosen yang kenaikan pangkatnya membutuhkan waktu antara 5-15 tahun. Sedangkan kenaikan jabatan akademik terdapat $30 \%$ dosen membutuhkan waktu 5 - 15 tahun. Berdasarkan data tersebut, penelitian ini penting dilaksanakan untuk menganalisis faktor-faktor yang mempengaruhi kenaikan pangkat dan jabatan dosen di Poltekkes Kemenkes Jakarta I.

\section{BAHAN DAN METODE Jenis Penelitian}

Jenis penelitian yang digunakan adalah analitik dengan desain cross sectional.

\section{Lokasi dan Waktu Penelitian}

Penelitian ini berlokasi di Poltekkes Kemenkes Jakarta I. Penelitian dilaksanakan pada bulan Juni - Oktober 2017

\section{Populasi dan Sampel.}

Populasi penelitian adalah seluruh dosen tetap yang memiliki jabatan fungsional. Penelitian ini dilakukan pada seluruh populasi.

\section{Pengumpulan Data}

Pengumpulan data dilakukan dengan menggunakan kuesioner skala likert dan Daftar Urut Kepangkatan pegawai per April 2017. Pernyataan pada kuesioner berupa pernyataan positif/favorable dengan lima pilihan jawaban yaitu skor 5 untuk pilihan jawaban sangat setuju, skor 4 untuk pilihan jawaban setuju, skor 3 untuk pilihan jawaban kurang setuju, skor 2 untuk pilihan jawaban tidak setuju dan skor 1 untuk pilihan jawaban sangat tidak setuju.

Kuesioner diuji validitasnya dengan Korelasi Product Moment dan uji reliabilitas dilakukan dengan Teknik Koefisien Alpha Cronbach. Kuesioner awal berjumlah 33 butir, setelah dilakukan uji validitas hanya 26 butir 
yang dinyatakan valid dan 7 butir dinyatakan tidak valid. Butir yang tidak valid karena memiliki nilai $r$ hitung lebih rendah dari $r$ tabel yaitu 0,339. Rentang nilai hasil uji validitas antara $0,352-0,725$. Pernyataan yang tidak valid dikeluarkan dari daftar sebelum dilakukan uji reliabilitas. Uji reliabilitas dilakukan terhadap 26 butir dan berdasarkan hasil uji seluruh pernyataan dinyatakan reliabel dengan nilai $r$ hitung lebih besar dari nilai $r$ tabel. Seluruh pernyataan dinyatakan reliabel dengan hasil uji statistik Alpa Cronbach dengan rentang nilai antara $0,668-0,706$.

\section{Pengolahan dan Analisis Data}

Pengolahan data dari kuesioner yang sebelumnya 5 kategori, digabungkan menjadi 2 kategori. Kategori Sangat Tidak Setuju, Tidak Setuju dan Kurang Setuju menjadi Kurang Baik dan kategori Setuju dan Sangat Setuju menjadi Baik. Pada tahap koding kelompok yang lebih beresiko yaitu kategori kurang baik diberi kode 1 dan yang baik diberi kode 0 .

Pengelompokan dilakukan dengan membuat total skor masing-masing komponen penilaian untuk masing-masing dosen kemudian ditentukan nilai Meannya. Apabila skor nilai masing-masing dosen kurang dari Mean maka diberi kategori baik dan apabila lebih dari atau sama dengan Mean dikategorikan kurang baik. Data selanjutnya dianalisis distribusi frekuensi, Chi-Square dan Regresi Logistik.

\section{HASIL}

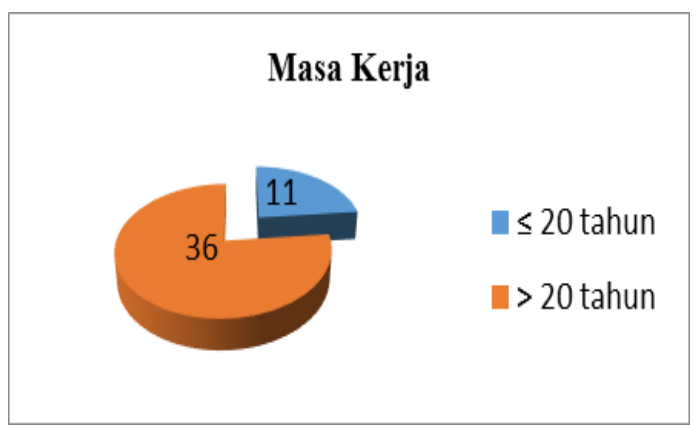

\section{Gambar 1. Distribusi Masa Kerja Dosen}

Responden penelitian pada saat pengambilan data dilakukan berjumlah 47 orang. Tidak semua dosen dapat mengisi kuesioner karena terdapat dosen yang sedang tugas belajar, pelatihan, cuti, atau ada keperluan dinas lainnya. Respons rate responden sebesar $78,33 \%$. Berdasarkan karakteristik responden yang terdiri dari masa kerja, usia dan jenis kelamin dapat dilihat pada gambar 1 .

Berdasarkan Gambar 1 diketahui bahwa sebagian besar dosen memiliki masa kerja lebih dari 20 tahun, sedangkan pada Gambar 2 diketahui bahwa sebagian besar dosen memiliki usia di atas 50 tahun.

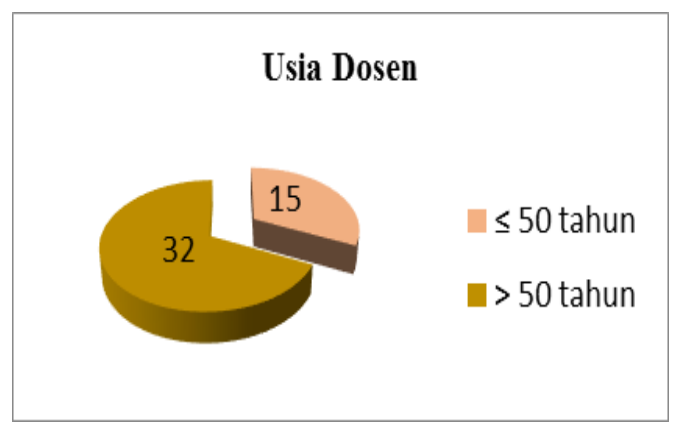

Gambar 2. Distribusi Usia Dosen

Variabel Komponen Penilaian PAK yang terdiri atas pendidikan dan pengajaran, penelitian, pengabdian kepada masyarakat dan kegiatan penunjang diukur dengan 21 pernyataan dalam kuesioner. Analisis univariat distribusi frekuensi komponen pendidikan dan pengajaran, penugasan dosen sebagai pembimbing tugas akhir $91,5 \%$ pelaksanaan baik dan $8,5 \%$ kurang baik. Penugasan dosen sebagai penguji tugas akhir mahasiswa $87,2 \%$ baik dan 12,8\% kurang baik. Dosen sebagai pembimbing PKL yang pelaksanaannya baik $80,9 \%$ dan kurang baik $19,1 \%$. Dosen melaksanakan pengembangan diri melalui pelatihan yang pelaksanaannya baik $66 \%$ dan $34 \%$ kurang baik. Dosen dengan tugas tambahan sebagai pimpinan sebesar 38,3\%.

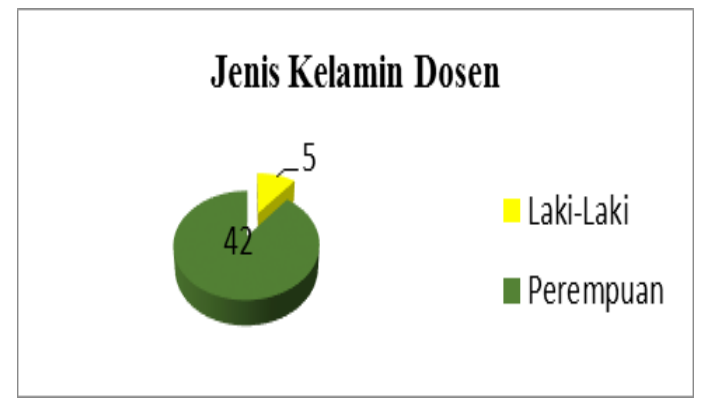

Gambar 3. Distribusi Jenis Kelamin Dosen

Distribusi frekuensi komponen penelitian $100 \%$ dosen melakukan penelitian setiap tahun, 76,6 \% dosen sebagai peneliti utama. Publikasi hasil penelitian 70,2\% dosen mempublikasikan di jurnal nasional dan hanya $38,29 \%$ yang mempublikasikan di jurnal 
internasional. $72,3 \%$ dosen sebagai penulis utama pada publikasi yang dilakukan dan 42,6 $\%$ dosen menulis buku sebagai karya ilmiah. Dosen yang memiliki Hak Atas Kekayaan Intelektual (HAKI) masih sangat rendah yaitu sebesar $14,9 \%$. Publikasi hasil penelitian melalui proceeding dilaksanakan oleh $48,9 \%$ dosen. Dosen yang menyatakan ketersediaan dana penelitian memadai sebesar $44,7 \%$ sedangkan dosen yang menyatakan bahwa dana yang disediakan untuk publikasi memadai berjumlah 25,5\%.

Komponen pengabdian kepada masyarakat dengan distribusi frekuensi dosen yang menyiapkan proposal kegiatan PKM terprogram setiap tahun berjumlah 93,6\%, dosen yang melakukan kegiatan PKM insidentil sebesar $74,5 \%$ dan dosen yang menyatakan dana kegiatan PKM yang disediakan memadai sebesar 57,4\%. Komponen kegiatan penunjang, dosen yang terlibat dalam kepengurusan dan kegiatan organisasi profesi sebesar 93,6\%, dosen yang mengikuti seminar/workshop sebesar $78,7 \%$. Dosen yang terlibat dalam kepanitiaan yang dilaksanakan oleh lembaga pemerintah sebesar 48,9\%.

Variabel berikutnya adalah sistem pengelolaan PAK yang dilaksanakan oleh tim penilai PAK. Diukur dengan 5 pernyataan. Analisis distribusi frekuensi diperoleh hasil bahwa 93,6\% dosen PAK nya terpenuhi setiap semester, $76,6 \%$ dosen menyimpan dokumen bukti fisik dengan rapi. Dosen yang bisa mengerjakan sendiri dengan mengentry nilai PAKnya sendiri sebesar 70,2\%. Penilaian PAK yang dilakukan oleh Tim Penilai hanya 44,7\% yang menyatakan responnya cepat dan $74,5 \%$ menyatakan waktu untuk pengusulan PAK lama.

Tahap selanjutnya data dianalisis bivariat dengan Chi Square untuk melakukan seleksi kandidat variabel yang dapat masuk ke uji Regresi Logistik. Hasil bivariat yang menghasilkan $\mathrm{p}$ value $<0,25$, maka variabel tersebut langsung masuk ke tahap multivariate (Hastono, 2017). Hasil uji Chi Square pada variabel karakteristik dosen dapat dilihat pada tabel dibawah ini:

Tabel 1. Hasil Seleksi Kandidat Bivariat pada Karakteristik Dosen

\begin{tabular}{|c|c|c|c|c|c|c|c|c|}
\hline \multirow{3}{*}{$\begin{array}{c}\text { Karakteristik } \\
\text { Dosen }\end{array}$} & \multicolumn{4}{|c|}{ Kenaikan Pangkat dan Jabatan } & \multirow{2}{*}{\multicolumn{2}{|c|}{ Total }} & \multirow{3}{*}{$\begin{array}{c}\text { OR } \\
(95 \% \mathrm{CI})\end{array}$} & \multirow{3}{*}{ p value } \\
\hline & \multicolumn{2}{|c|}{ Tepat Waktu } & \multicolumn{2}{|c|}{ Tidak Tepat Waktu } & & & & \\
\hline & $\mathbf{n}$ & $\%$ & $\mathbf{n}$ & $\%$ & $\mathbf{N}$ & $\%$ & & \\
\hline \multicolumn{9}{|l|}{ Masa Kerja } \\
\hline$\leq 20$ tahun & 5 & 45,5 & 6 & 54,5 & 11 & 100 & \multirow{3}{*}{$\begin{array}{c}0,746 \\
0,1-2,8\end{array}$} & \multirow[b]{3}{*}{0,936} \\
\hline$>20$ tahun & 19 & 52,8 & 17 & 47,2 & 36 & 100 & & \\
\hline Jumlah & 24 & 51,1 & 23 & 48,9 & 47 & 100 & & \\
\hline \multicolumn{9}{|l|}{ Usia } \\
\hline$\leq 50$ tahun & 8 & 53,3 & 7 & 46,7 & 15 & 100 & \multirow{3}{*}{$\begin{array}{c}1,143 \\
0,3-3,9\end{array}$} & \multirow{3}{*}{1,00} \\
\hline$>50$ tahun & 16 & 50 & 16 & 50 & 32 & 100 & & \\
\hline Jumlah & 24 & 51,1 & 23 & 48,9 & 47 & 100 & & \\
\hline \multicolumn{9}{|l|}{ Jenis Kelamin } \\
\hline Laki-laki & 4 & 80 & 1 & 20 & 5 & 100 & \multirow{3}{*}{$\begin{array}{c}4,400 \\
0,4-42,7\end{array}$} & \multirow{3}{*}{0,187} \\
\hline Perempuan & 20 & 47,6 & 22 & 52,4 & 42 & 100 & & \\
\hline Jumlah & 24 & 51,1 & 23 & 48,9 & 47 & 100 & & \\
\hline
\end{tabular}

Berdasarkan Tabel 1 diketahui bahwa variabel yang memiliki nilai $\mathrm{p}$ value $<0,25$ hanya variabel jenis kelamin, sehingga variabel tersebut dapat masuk ke analisis regresi logistik. Seleksi kandidat selanjutnya dilakukan pada komponen penilaian PAK dan komponen sistem pengelolaan PAK dapat dilihat pada tabel 2 .
Berdasarkan Tabel 2 diketahui bahwa seluruh variabel memiliki nilai $p$ value $<0,25$ (pendidikan dan pengajaran, penelitian, pengabdian kepada masyarakat, kegiatan penunjang dan sistem pengelolaan PAK). Tahap selanjutnya data dianalisis dengan Regresi Logistik dengan kandidat 6 variabel. 
Tabel 2. Hasil Seleksi Kandidat pada Komponen Penilaian PAK dan Sistem Pengelolaan PAK

\begin{tabular}{|c|c|c|c|c|c|c|c|c|}
\hline \multirow{3}{*}{$\begin{array}{c}\text { Komponen } \\
\text { Penilaian }\end{array}$} & \multicolumn{4}{|c|}{ Kenaikan Pangkat dan Jabatan } & \multirow{2}{*}{\multicolumn{2}{|c|}{ Total }} & \multirow{3}{*}{$\underset{(95 \% \mathrm{CI})}{\text { OR }}$} & \multirow{3}{*}{$\begin{array}{c}\mathbf{p} \\
\text { value }\end{array}$} \\
\hline & \multicolumn{2}{|c|}{ Tepat waktu } & \multicolumn{2}{|c|}{$\overline{\text { Tidak tepat waktu }}$} & & & & \\
\hline & $\mathbf{n}$ & $\%$ & $\mathbf{n}$ & $\%$ & $\mathbf{N}$ & $\%$ & & \\
\hline \multicolumn{9}{|c|}{ Pendidikan dan pengajaran } \\
\hline Baik & 18 & 66,7 & 9 & 33,3 & 27 & 100 & \multirow{3}{*}{$\begin{array}{c}0,4667 \\
1,3-16,2\end{array}$} & \multirow{3}{*}{0,028} \\
\hline Kurang baik & 6 & 30 & 14 & 70 & 20 & 100 & & \\
\hline Jumlah & 24 & 51,1 & 23 & 48,9 & 47 & 100 & & \\
\hline \multicolumn{9}{|l|}{ Penelitian } \\
\hline Baik & 16 & 84,2 & 3 & 15,8 & 19 & 100 & \multirow{3}{*}{$\begin{array}{c}13,333 \\
3,0-58,6\end{array}$} & \multirow{3}{*}{0,001} \\
\hline Kurang baik & 8 & 28,6 & 20 & 71,4 & 28 & 100 & & \\
\hline Jumlah & 24 & 51,1 & 23 & 48,9 & 47 & 100 & & \\
\hline \multicolumn{9}{|c|}{ Pengabdian kepada Masyarakat } \\
\hline Baik & 13 & 65 & 7 & 35 & 20 & 100 & \multirow{3}{*}{$\begin{array}{c}2,701 \\
0,8-8,9\end{array}$} & \multirow{3}{*}{0,177} \\
\hline Kurang baik & 11 & 40,7 & 16 & 59,3 & 27 & 100 & & \\
\hline Jumlah & 24 & 51,1 & 23 & 48,9 & 47 & 100 & & \\
\hline \multicolumn{9}{|c|}{ Kegiatan Penunjang } \\
\hline Baik & 15 & 75 & 5 & 25 & 20 & 100 & \multirow{3}{*}{$\begin{array}{c}6,000 \\
1,6-21,8\end{array}$} & \multirow{3}{*}{0,011} \\
\hline Kurang baik & 9 & 33,3 & 18 & 66,7 & 27 & 100 & & \\
\hline Jumlah & 24 & 51,1 & 23 & 48,9 & 47 & 100 & & \\
\hline \multicolumn{9}{|c|}{ Sistem Pengelolaan PAK } \\
\hline Baik & 15 & 88,2 & 2 & 11,8 & 17 & 100 & \multirow{3}{*}{$\begin{array}{c}17,500 \\
3,2-92,8\end{array}$} & \multirow{3}{*}{0,000} \\
\hline Kurang baik & 9 & 30 & 21 & 70 & 30 & 100 & & \\
\hline Jumlah & 24 & 51,1 & 23 & 48,9 & 47 & 100 & & \\
\hline
\end{tabular}

Pada tahap multivariabel, semua variabel yang sudah lolos tahap seleksi bivariat dilakukan analisis secara bersama-sama dalam model. Hasil pemodelan sebagai berikut:

Tabel 3. Pemodelan Pertama Regresi Logistik

\begin{tabular}{lcccc}
\hline \multicolumn{1}{c}{ Variabel } & B & p value & OR & 95\% CI \\
\hline Jenis kelamin & 2,987 & 0,301 & 19,655 & $0,070-5523,824$ \\
Pendidikan dan pengajaran & 3,217 & 0,031 & 24,961 & $1,337-465,847$ \\
Penelitian & 4,031 & 0,013 & 56,323 & $2,300-1379,043$ \\
Pengabdian kepada Masyarakat & 0769 & 0,481 & 2,157 & $0,254-18,352$ \\
Kegiatan penunjang & 1,772 & 0,090 & 5,883 & $0,757-45,737$ \\
Sistem pengelolaan PAK & 3,461 & 0,012 & 31,865 & $2,131-476,370$ \\
\hline
\end{tabular}

Langkah selanjutnya dilakukan eliminasi/ seleksi variabel yang memiliki $\mathrm{p}$ value $>0,05$. Dari pemodelan pertama tiga variabel yang memiliki $\mathrm{p}$ value > 0,05 yaitu jenis kelamin, pengabdian kepada mayarakat dan kegiatan penunjang. Eliminasi pertama, variabel yang memiliki $\mathrm{p}$ value $>0,05$ dan terbesar dikeluarkan dari model yaitu pengabdian kepada masyarakat. Pemodelan kedua variabel yang memiliki $\mathrm{p}$ value $>0,05$ yaitu jenis kelamin dan kegiatan penunjang. Variabel yang dieliminasi memiliki $\mathrm{p}$ value $>0,05$ dan terbesar yaitu jenis kelamin. Langkah selanjutnya jenis kelamin dikeluarkan dari pemodelan. Pemodelan ketiga variabel yang memiliki $\mathrm{p}$ value > 0,05 yaitu kegiatan penunjang. Langkah selanjutnya kegiatan penunjang dikeluarkan dari pemodelan sampai diperoleh pemodelan akhir sebagai berikut: 
Tabel 4. Pemodelan Akhir Regresi Logistik

\begin{tabular}{lcccc}
\hline \multicolumn{1}{c}{ Variabel } & B & p value & OR & 95\% CI \\
\hline Pendidikan dan pengajaran & 2,986 & 0,024 & 19,808 & $1,492-263,000$ \\
Penelitian & 3,709 & 0,007 & 40,798 & $2,705-615,398$ \\
Sistem pengelolaan PAK & 2,992 & 0,004 & 19,918 & $1,781-222,729$ \\
\hline
\end{tabular}

Hasil pemodelan akhir ada tiga variabel yang berhubungan dengan kenaikan pangkat dan jabatan dosen yaitu pendidikan dan pengajaran, penelitian dan sistem pengelolaan PAK. Untuk mengetahui variabel yang paling besar pengaruhnya dilihat pada nilai OR pada variabel yang signifikan. Semakin besar nilainya, semakin besar pengaruhnya. Pada hasil penelitian ini, variabel yang memiliki pengaruh terbesar terhadap kenaikan pangkat dan jabatan dosen adalah penelitian dengan nilai OR 40,798.

\section{PEMBAHASAN}

Berdasarkan hasil penelitian yang dilakukan dengan variabel bebas karakteristik dosen, komponen penilaian PAK dan sistem pengelolaan PAK diperoleh hasil bahwa karakteristik dosen tidak memiliki hubungan yang signifikan dengan kenaikan pangkat dan jabatan dosen. Hasil penelitian ini sesuai dengan hasil penelitian yang dilakukan di Harvard Medical School bahwa tidak ada perbedaan jenis kelamin yang signifikan dalam pemberian penghargaan National Institutes of Health (NIH) R01 di antara 5445 instruktur dan asisten profesor. Variabel yang diteliti terkait demografi, metrik produktivitas penelitian, dan karakteristik profesional (Warner, Erica T.; Carapinha, René; Weber, Griffin M.; Hill, Emorcia V.; Reede, 2017). Dari hal ini dapat disimpulkan bahwa setiap orang memiliki peluang yang sama sebagaimana kenaikan pangkat dan jabatan sebagai penghargaan atas kinerja dosen.

Komponen penilaian PAK pendidikan dan pengajaran, penelitian, pengabdian kepada masyarakat dan kegiatan penunjang, dari 4 variabel ini yang memiliki hubungan yang signifikan terhadap kenaikan pangkat dan jabatan dosen salah satunya adalah pendidikan dan pengajaran. Komponen pendidikan dan pengajaran dapat dipenuhi dosen dengan melakukan perkuliahan dan bimbingan praktek baik laboratorium maupun lapangan, bimbingan tugas akhir mahasiswa dan kegiatan lainnya. Kegiatan lain untuk memenuhi komponen ini yaitu dengan mengikuti pelatihan untuk meningkatkan kompetensi sesuai dengan bidang profesinya, dapat juga dipenuhi dengan tugas tambahan yaitu menduduki jabatan sebagai pimpinan. Dengan hasil OR 19,808 artinya dosen yang memiliki kinerja baik memiliki peluang naik pangkat dan jabatan tepat waktu sebanyak 19,808 kali dibandingkan dengan dosen yang memiliki kinerja kurang baik.

Penelitian merupakan komponen penilaian PAK selanjutnya. Penelitian memiliki hubungan yang signifikan dengan kenaikan pangkat dan jabatan dosen. Penelitian memiliki hubungan yang paling besar dengan kenaikan pangkat dan jabatan dosen ditandai dengan nilai OR tertingi dibandingkan dengan nilai OR variabel lain yang signifikan. Menghasilkan karya ilmiah merupakan suatu tantangan yang cukup berat bagi sebagian besar dosen karena membutuhkan upaya dan pemikiran yang serius karena rangkaian yang cukup panjang dari mempersiapkan proposal, pengumpulan dan pengolahan data, menyusun laporan penelitian dan publikasi. Hasil penelitian ini sesuai dengan hasil evaluasi dari Kementerian Riset dan Teknologi tahun 2017 bahwa produktifitas dosen di Indonesia belum memuaskan terkait publikasi ilmiah dan menduduki ranking 4 di Asia Tenggara (Kopertis12, 2017). Berdasarkan hasil penelitian Rehabilitation Research and Training Center Universitas Langston, Amerika Serikat bahwa faktor-faktor yang diidentifikasi mempengaruhi produktifitas penelitian adalah beban pengajaran dan layanan yang berat, masalah manajemen waktu, kurangnya kolaborasi, mentor terbatas, sumber keuangan yang tidak mencukupi, budaya administrasi dan penelitian yang tidak memadai, dan dana negara dan donor yang tidak mencukupi dan juga sumber yang relevan sebagai bahan informasi untuk meningkatkan produktivitas ilmiah (Aref et al., 2017). Hasil ini juga sesuai dengan hasil 
penelitian yang dilakukan di Makerere University College of Health Sciences, Uganda, prioritas yang dibutuhkan untuk memperbaiki hasil penelitian, adalah (1) program pengembangan karir (2) pengembangan keterampilan dalam metode penelitian dan penulisan ilmiah, (3) tersedianya waktu yang memadai untuk kegiatan penelitian, (4) kesempatan untuk penelitian kolaboratif, dan (5) penggunaan rencana pengembangan individu (Nakanjako et al., 2017).

$$
\text { Variabel pengabdian kepada }
$$

masyarakat tidak memiliki hubungan yang signifikan dengan kenaikan pangkat dan jabatan dosen. Berdasarkan Pasal 1 Permenristekdikti Nomor 44 tahun 2015 tentang Standar Nasional Pendidikan Tinggi dalam pasal tersebut dijelaskan bahwa Skema riset dan pengabdian kepada masyarakat harus berbasis kepada Rencana Induk Riset Nasional yang merupakan arah kebijakan riset pada tingkat nasional dan menjadi prioritas program pemerintah dalam mendorong hilirisasi dan komersialisasi hasil riset sehingga lebih bermanfaat bagi masyarakat dan mendorong perekonomian bangsa. Berdasarkan aturan di atas penelitian dan pengabdian kepada masyarakat memiliki standar yang sama dan hasil riset selanjutnya dimanfaatkan untuk kegiatan pengdian kepada masyarakat (Direktorat Riset PkM, 2017).

Dalam implementasinya, penerapan standar penelitian belum sama ketatnya dalam penerapan standar pengabdian kepada masyarakat, sehingga dosen lebih mudah memenuhi persyaratan dalam penilaian PAK terkait pengabdian kepada masyarakat dibandingkan persyaratan terkait penelitian dan publikasi karya ilmiah. Hal ini kemungkinan menjadi penyebab pengabdian masyarakat tidak memiliki hubungan yang siginifikan dengan kenaikan pangkat dan jabatan dosen. Variabel kegiatan penunjang juga tidak memiliki hubungan yang signifikan dengan kenaikan pangkat dan jabatan dosen. Untuk memenuhi komponen penilaian PAK ini, dosen memiliki banyak sumber kegiatan yang dapat digunakan untuk memenuhi komponen ini dengan syarat dosen yang bersangkutan aktif mengikuti kegiatan-kegiatan penunjang.

Sistem pengelolaan PAK memiliki hubungan yang signifikan dengan kenaikan pangkat dan jabatan dosen. Pemahaman dosen terhadap persyaratan kenaikan pangkat dan jabatan dosen sangat penting karena berhubungan dengan strategi yang akan dilakukan dosen setiap semester agar dapat memenuhi persyaratan penilaian yang dipersyaratkan. Kemampuan mengentri sendiri setiap komponen penilaian dan menyiapkan bukti fisik yang dipersyaratkan juga berpengaruh terhadap kecepatan naik pangkat dan jabatan dosen karena kecepatannya dapat diatur sendiri oleh dosen yang bersangkutan dan tidak tergantung kepada orang lain.Hasil penelitian ini sesuai dengan hasil penelitian pada kinerja dosen di Kalimantan Selatan bahwa dosen yang memiliki nilai pribadi yang kuat, memiliki kemampuan untuk berfikir analitis, perilaku terstruktur, hubungan vertikal dan horizontal yang berkualitas akan mampu menyelesaikan tugas sesuai dengan ketentuan yang ada (Kuswandi, Sundjoto, Noor, \& Purwanto, 2015).

Dosen yang membutuhkan waktu naik pangkat 5 - 15 tahun berada pada jabatan akademik Lektor Golongan III/d dan jabatan akademik Lektor KepalaGolongan IV. Hal ini disebabkan karena untuk dosen yang akan naik ke jabatan akademik Lektor Kepala dan naik pangkat dengan jabatan Lektor Kepala dokumen usulan harus diajukan ke Kemenristekditi dengan persyaratan yang ketat terutama terkait dengan publikasi karya ilmiah di jurnal nasional terakreditasi dan jurnal internasional. Hal ini juga menjadi salah satu penyebab lamanya waktu yang dibutuhkan untuk naik pangkat dan jabatan dosen.

\section{KESIMPULAN DAN SARAN}

Berdasarkan hasil penelitian dapat disimpulkan bahwa variabel karakteristik dosen tidak memiliki hubungan yang signifikan dengan kenaikan pangkat dan jabatan dosen. Faktor penentu kenaikan pangkat dan jabatan dosen adalah pendidikan dan pengajaran, penelitian serta sistem pengelolaan PAK.

Berdasarkan hasil penelitian saran yang dapat diberikan adalah memberi kesempatan pelatihan untuk peningkatan kompetensi kepada setiap dosen sesuai dengan bidang profesinya agar dapat meningkatkan kemampuannya dalam pengelolaan PAK bidang pendidikan dan pengajaran, memberikan pelatihan penulisan publikasi karya ilmiah yang lebih intensif kepada dosen agar dapat meningkatkan produktifitas dosen dalam mempublikasikan karya ilmiahnya serta memberikan penghargaan bagi dosen yang melakukan publikasi karya 
ilmiah untuk meningkatkan motivasi untuk berkarya. Kegiatan pengabdian masyarakat diupayakan dilaksanakan sesuai dengan Standar Nasional Pendidikan Tinggi yang telah ditetapkan, agar hasil penelitian lebih bermanfaat dan digunakan untuk kegiatan pengabdian masyarakat. Tim penilai PAK agar mengkaji kembali mekanisme pengusulan dan penilaian PAK terutama untuk mempersingkat waktu usulan dan penilaian.

\section{DAFTAR PUSTAKA}

Aref, F., Manyibe, E. O., Washington, A. L., Johnson, J., Davis, D., Eugene-cross, K., \& Moore, C. A. (2017). Research Productivity in Rehabilitation, Disability, and Allied Health Programs: A Focus Group Perspective on Minority-Serving Institutions, 31(3), 194-207.

Direktorat Riset PkM. (2017). Panduan Pelaksanaan Penelitian dan Pengabdian Kepada Masyarakat di Perguruan Tinggi. Jakarta: Kemenristekdikti.

Hastono, S. P. (2017). Analisis Data. Jakarta: FKM-UI.

Kopertis12. (2017). Publikasi Ilmiah Indonesia
Ranking 4 Asia Tenggara. Retrieved from www.kopertis12.or.id

Kuswandi, Sundjoto, Noor, A., \& Purwanto. (2015). Effects of Transformational Leadership, Personal values, Job Satisfaction on Lecturer Performance. Journal of Arts, Science \& Commerce, VI(April 2015), 84-93.

Nakanjako, D., Akena, D., Kaye, D. K., Tumwine, J., Okello, E., Nakimuli, A., Sewankambo, N. K. (2017). A need to accelerate health research productivity in an African University: the case of Makerere University College of Health Sciences, 1-10. https://doi.org/10.1186/ s12961-017-0196-6.

Warner, Erica T.; Carapinha, René; Weber, Griffin M.; Hill, Emorcia V.; Reede, J. Y. (2017). Gender Differences in Receipt of National Institutes of Health R01 Grants Among Junior Faculty at an Academic Medical Center: The Role of Connectivity, Rank, and Research Productivity. Journal of Women's Health, 26(10), 1086-1093. (8p). 